ISBN: 978-1-948012-12-6

\title{
ONLINE SIMULATION OF SHELL-AND-TUBE HEAT EXCHANGER BASED ON CONFIGURATION SOFTWARE
}

\author{
Tian Ao ${ }^{1}$, Wang Xing1, Hao Liwen ${ }^{1}$, Cao Yubo ${ }^{1}$, Yang Ying ${ }^{2 *}$ \\ ${ }^{1}$ School of Information and Control Engineering, Jilin Institute of Chemical Technology Chengde Street 45, Jilin, China. \\ ${ }^{2}$ School of Petrochemical Technology, Jilin Institute of Chemical Technology Chengde Street 45, Jilin, China \\ *Corresponding Author Email: yangying 1972@163.com
}

This is an open access article distributed under the Creative Commons Attribution License, which permits unrestricted use, distribution, and reproduction in any medium, provided the original work is properly cited.

\section{ARTICLE DETAILS}

\section{Article History:}

Received 26 June 2018 Accepted 2 July 2018

\section{ABSTRACT}

Taking the shell-and-tube heat exchanger as the research object, based on the conservation of energy, the dynamic mathematical model of the heat exchanger is established through the mechanism analysis method. Using configuration software to draw the simulation interface, the differential mathematical model is programmed. The dynamic response of the outlet temperature of the heat exchanger cold fluid is simulated during the flowrate and temperature of hot fluid change. By using the simulation program, the running parameters can be modified and adjusted in real time, and the on-line simulation of heat exchanger process is realized.

\section{KEYWORDS}

Dynamic model, heat exchanger, simulation, online.

\section{INTRODUCTION}

Heat exchanger is a commonly used device for heat exchange between different media, and it is one of the common operating units in continuous production. Its research and application are paid great attention at home and abroad, and it is one of the most active research fields in heat transfer technology [1-4]. Since there are various unstable factors in the heat exchange process, the disturbance of temperature or flowrate occurs frequently, which is very unfavorable to the stable operation of the heat exchanger. In order to ensure the stable operation of the heat exchanger, the heat exchanger must be effectively controlled. Therefore, the dynamic simulation of the heat exchanger has a certain engineering significance [57].

\section{HEAT EXCHANGER MODELING}

The shell-and-tube heat exchanger is taken as the research object shown in Figure 1. Some conditions are assumed as follows [8]

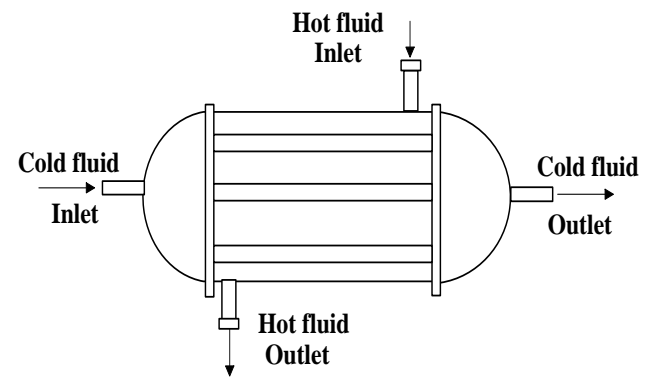

Figure 1: Configuration of shell-and-tube heat exchanger

The two fluids in the heat exchanger are incompressible fluids, called hot fluid and cold fluid respectively. The cold fluid is expressed as $c$, while hot fluid as $h$. The mass flowrate is expressed as $W, \mathrm{~kg} / \mathrm{s}, W_{c}$ for cold fluid and $W_{h}$ for hot fluid(the following is the same); The constant pressure specific heat is $C p, \mathrm{~J} /(\mathrm{kg} \cdot \mathrm{K})$; The density is $\rho, \mathrm{kg} / \mathrm{m}^{3}$; The inlet and outlet temperatures are Tin and Tout, K; The fluid temperature at any position in the heat exchanger is $T, \mathrm{~K}$; The cross-sectional areas of heat exchanger tube side and shell side are $A c$ and $A h, \mathrm{~m}^{2}$; The tube length of the heat exchanger is $X, \mathrm{~m}$; The total heat transfer coefficient of the heat exchanger is $U, \mathrm{~W} /\left(\mathrm{m}^{2} \cdot \mathrm{k}\right)$. The heat exchanger adopts countercurrent heat transfer. In addition, we assume:

(1) The specific heat capacity of the heat exchanger is negligible.

(2) The heat emitted to the surroundings during heat transfer can be ignored.

In the dynamic process of heat exchange, the heat balance equation can be expressed as $[9,10]$ :

$$
\mathrm{A}_{\mathrm{c}} \mathrm{x} \rho_{\mathrm{c}} \mathrm{C}_{\mathrm{pc}} \mathrm{T}_{\mathrm{c}}=\mathrm{W}_{\mathrm{c}} \mathrm{C}_{\mathrm{pc}} \mathrm{T}_{\text {cout }}-\mathrm{W}_{\mathrm{c}} \mathrm{C}_{\mathrm{pc}} \mathrm{T}_{\mathrm{cin}}+\mathrm{U} \frac{\mathrm{W}_{\mathrm{h}}}{\rho_{\mathrm{h}}}\left(\mathrm{T}_{\mathrm{h}}-\mathrm{T}_{\mathrm{c}}\right)
$$

An analysis is made on micro segment of the heat exchanger, as shown in Figure. 2. When the temperature and flowrate of the heat exchanger are disturbed, the temperature distribution function of the cold fluid at any given time is obtained. That's the dynamic response of temperature and time.

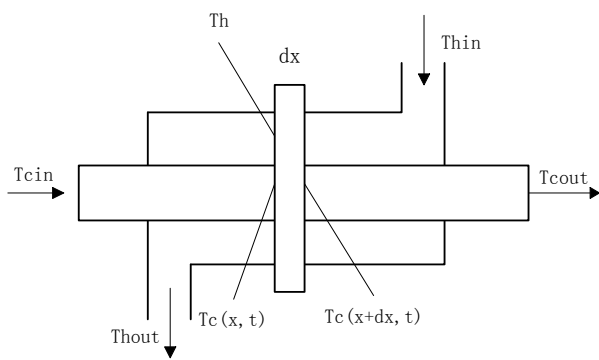

Figure 2: The temperature distribution of the micro segment $\mathrm{dx}$

Analysis on the $\mathrm{dx}$ of the heat exchanger micro segment, the heat balance is calculated according to the dynamic heat balance equation, then the dynamic expression of the heat exchanger is:

$\frac{\partial}{\partial \mathrm{t}} \mathrm{A}_{\mathrm{c}} \mathrm{dx} \rho_{\mathrm{c}} \mathrm{C}_{\mathrm{pc}} \mathrm{T}_{\mathrm{c}}=\left.\mathrm{W}_{\mathrm{c}} \mathrm{C}_{\mathrm{pc}} \mathrm{T}_{\mathrm{c}}\right|_{\mathrm{x}}-\left.\mathrm{W}_{\mathrm{c}} \mathrm{C}_{\mathrm{pc}} \mathrm{T}_{\mathrm{c}}\right|_{\mathrm{x}+\mathrm{dx}}+\mathrm{U} \frac{\mathrm{W}_{\mathrm{h}}}{\rho_{\mathrm{h}}}\left(\mathrm{T}_{\mathrm{h}}-\mathrm{T}_{c}\right)$

Because $A_{C} 、 d x, \rho_{c}, \rho_{t}, C_{p c}, W_{c}, W_{h}$ can be regarded as a constant, the formula (2) can be simplified as: 


$$
\frac{\partial T_{c}}{\partial t}=\frac{W_{c}}{A_{c} \rho_{c}} \frac{\partial T_{c}}{d x}+\frac{U W_{h}\left(T_{h}-T_{c}\right)}{\rho_{c} \rho_{h} A_{c} C_{p c}}
$$

The formula (3) is the function relation of the fluid temperature $T c$ in the tube with the time and tube length. Because the formula contains the shell fluid temperature $T h, T h$ also changes with time and length, therefore, a mathematical model of fluid temperature $T h$ for shell and tube is also needed. The mathematical model of shell fluid temperature can be obtained by using the same method:

$$
\frac{\partial T_{h}}{\partial t}=\frac{W_{h}}{A_{h} \rho_{h}} \frac{\partial T_{h}}{\partial x}-\frac{U W_{h}\left(T_{h}-T_{c}\right)}{\rho_{h}^{2} A_{c} C_{p c}}
$$

Formula (3) and formula (4) constitute the dynamic mathematical model of heat exchanger.

\section{SOLUTION AND SIMULATION OF THE DYNAMIC MODEL OF HEAT EXCHANGER}

\subsection{Solution of dynamic model}

The dynamic mathematical model of the heat exchanger is a partial differential equation, so the forward difference method is used to transform the partial differential equation into a difference equation. So for the fluid in the pipe:

$$
\begin{aligned}
& \frac{\partial T_{c}}{\partial t}=\frac{T_{c m+1}-T_{c m}}{\triangle t} \\
& \frac{\partial \mathrm{T}_{\mathrm{c}}}{\partial \mathrm{x}}=\frac{\mathrm{T}_{\mathrm{cm}+1}-\mathrm{T}_{\mathrm{cm}}}{\triangle \mathrm{x}}
\end{aligned}
$$

In the same way, so for the fluid in the shell:

$$
\begin{aligned}
\frac{\partial \mathrm{T}_{\mathrm{h}}}{\partial \mathrm{t}} & =\frac{\mathrm{T}_{\mathrm{hm}+1}-\mathrm{T}_{\mathrm{hm}}}{\triangle \mathrm{t}} \\
\frac{\partial T_{h}}{\partial x} & =\frac{T_{h m+1}-T_{h m}}{\triangle x}
\end{aligned}
$$

The difference equations can be obtained:

$$
\begin{aligned}
& T_{c}=T_{c+1}-\frac{W_{c} \triangle t}{A_{c} \rho_{c} \triangle x}\left(T_{c+1}-T_{c}\right)+\frac{U_{h}}{\rho_{c} \rho_{h} A_{c} C_{p c} \triangle x}\left(T_{h}-T_{c}\right) \\
& T_{h}=T_{h+1}-\frac{W_{h} \triangle t}{A_{h} \rho_{h} \triangle x}\left(T_{h+1}-T_{h}\right)+\frac{U_{h}}{\rho_{h}^{2} A_{h} C_{p h} \triangle x}\left(T_{h}-T_{c}\right)
\end{aligned}
$$

\subsection{System parameters and simulation}

Using the configuration software to draw the simulation operation interface, which includes three parts: real-time curves, parameters setting and state parameters display. The part of state parameters displays the process parameters such as the real-time temperature of the inlet and outlet of the heat exchanger, while the temperatures of the inlet and outlet are also displayed in the X-Y curves. The part of parameters setting displays the parameters of heat exchanger system in digital mode, and the system parameters such as the flow, density, specific heat and area can be modified in real time.

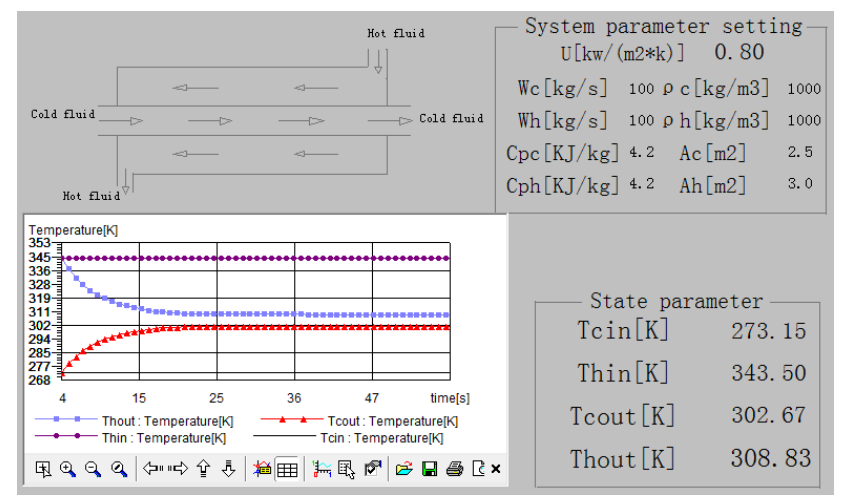

Hot water and cold water are selected as the hot fluid in shell side and cold fluid in tube side respectively. The temperature, density and constant pressure specific heat of cold fluid in tube side are $273.15 \mathrm{~K}, 1000 \mathrm{Kg} / \mathrm{m}^{3}$ and $4.2 \mathrm{KJ} / \mathrm{Kg}$ respectively; and for hot fluid in shell side are $373.15 \mathrm{~K}$, $1000 \mathrm{Kg} / \mathrm{m}^{3}$ and $4.2 \mathrm{KJ} / \mathrm{Kg}$ respectively.

In the absence of disturbance, the flowrates of both the hot fluid and the cold fluid are $100 \mathrm{~kg} / \mathrm{s}$. At the same time, set $100 \mathrm{~kg} / \mathrm{s}$ as unit flowrate. Keeping the temperature of hot fluid unchanged, the inlet flowrate of the hot fluid generates a step disturbance when the steady state is not reached. When the outlet temperature of the cold fluid reaches a steady state, the dynamic response of the cold fluid temperature of the heat exchanger is shown in Figure 4.

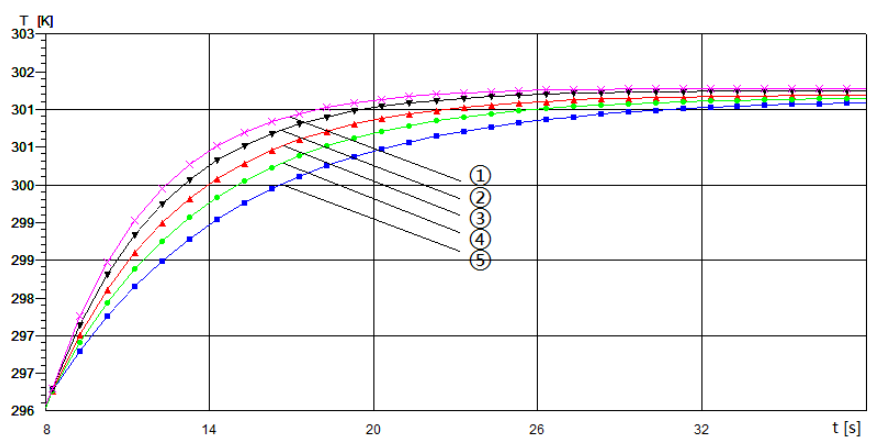

Figure 4: Before the hot exchanger reached steady state Temperature dynamic response of

step cold fluid when hot fluid flowrate has a step disturbance

(1) -1.2 times unit flowrate; (2) -1.1 times unit flowrate; (3)-unit flowrate; (4) -0.9 times unit flowrate; (5) -0.8 times unit flowrate

Keeping the hot fluid temperature unchanged, the hot fluid inlet flowrate has a step disturbance after reaching steady state. When the outlet temperature of the cold fluid reaches a new stable state, the dynamic response of the cold fluid temperature of the heat exchanger is shown in Figure 5.

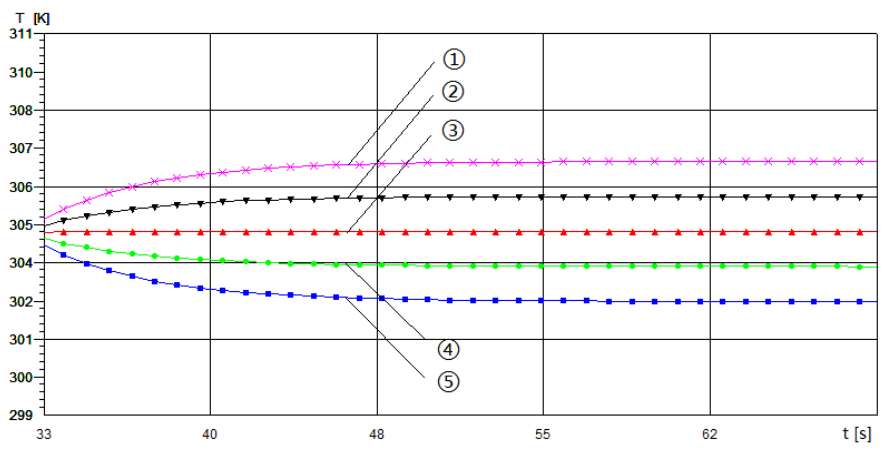

Figure 5: After hot exchenger reached steady state Dynamic response of cold fluid temperature when hot fluid flowrate has a step disturbance

(1)-1.2 times unit flowrate ; (2) -1.1 times unit flowrate ; (3)unit flowrate ; (4)-0.9 times unit flowrate ; (5) -0.8 times unit flowrate

From Figure 4 and Figure 5 it can be seen that the dynamic response of the cold fluid outlet temperature under different perturbations of the inlet flowrate of the hot fluid is approximately symmetrical. At the same time, the cold fluid temperature increases with the increase of the inlet flowrate of the hot fluid.

Keeping the flowrate of the hot fluid constant, the inlet temperature of the hot fluid generates a step disturbance after reaching the stable state. When the outlet temperature of the cold fluid reaches a new stable state, the dynamic response of the cold fluid temperature of the heat exchanger is shown in Figure 6.

Figure 3: Simulation software interface 


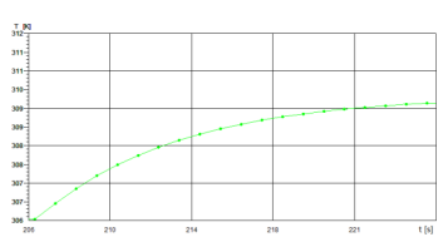

(a) Increased thermal fluid temperature

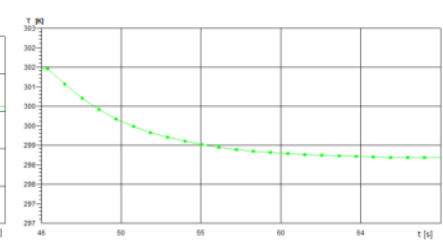

(b) Reduced hot fluid temperature
Figure 6: After hot exchanger reached steady state Dynamic response of cold fluid temperature when hot fluid temperature has a step disturbance

From Figure. 6 we know that the temperature of the hot fluid is the main factor affecting the temperature of the cold fluid, and the temperature of the cold fluid varies with the temperature of the hot fluid.

\section{CONCLUSION}

Through the mechanism analysis, the mathematical model of the temperature and control variables of the fluid outlet in the heat exchanger tube is established. The simulation program of the fluid outlet temperature, the outlet temperatures of shell and tube and the simulation interface based on configuration software are compiled respectively. The simulation program can modify and adjust the operating parameters of the system in real time, so as to realize the dynamic on-line simulation of the heat exchanger. The simulation process is basically consistent with the control process of the actual plant. The simulation curve and simulation data have a high reference value for the study of the heat exchange system.

\section{REFERENCE}

[1] Sun, F. 2003. Prasad RC.A Transient Experimental Method to Determine the Overall Heat Transfer Coefficient in a Concentric Tube Heat Exchanger [J]. Int. Comm. Heat Mass Transfer, 30 (5), 603-614.
[2] Lei, F., Kelun, T., Huabin, W., Weihui, W., Ling, F. 2012. Numerical Simulation of Shell and Tube Heat Exchanger Fluid Flow and Coupled Heat Transfer [J]. Chemical Industry and Engineering Progress, 31 (11), 23842389.

[3] Zhenga, H., Xuana, G., Xiaoyua, S., Jua, L., Bin-Sheng, W. 2017. A coupled immersed boundary method for simulating multiphase flows. Acta Electronica Malaysia, 1 (1), 05-08.

[4] Ting, G. 2013. Research on the Shell Side Flow Field and Performance for the Shell and Tube Heat Exchanger [D]. Anhui University of Science And Technology.

[5] Minshan, L., Qiwu, D., Qian, L. 2006. Numerical Simulation and Structural Optimization of Flowing Field in Shell Side of Heat Exchanger with Baffle [J]. Process Equipment and Piping, (02), 24-27+31.

[6] Minglu, L., Xin, Y., Yao, Z., Yan, Z. 2018. Current Situation Analysis and Classified Application of Heat Exchangers [J]. Contemporary Chemical Industry, 47 (03), 582-584.

[7] Kaifeng, W. 2016. Simultaneous Optimization of Shell-and-tube Heatexchanger Design and Heat Exchanger Network Synthesis [D]. Dalian University of Technology.

[8] Shiming, Y., Quan, T.W. 2006. Heat transfer [M]. Beijing: Higher Education Press.

[9] Ying, Y., Yubo, C., Weiping, G. 2010. Online Simulation of Direct Heater Automation Control System [J]. Control and Instruments in Chemical Industry, 37 (02), 28-30.

[10] Wen, Z., Qi, K., Ximing, Y. 2001. Analysis of dynamic characteristics of shell and tube heat exchangers [J]. Jiangxi Energy, (01), 29-32. 